\title{
O engajamento de Ruth Escobar nas lutas feministas: III Festival Internacional de Teatro
}

Eder Sumariva Rodrigues ${ }^{1}$

Vera Collaço ${ }^{2}$

Resumo

Este artigo tem como objetivo debater algumas das produções teatrais presentes no III Festival Internacional de Teatro (FIT), realizado no período de $1 .^{\circ}$ a 16 de agosto de 1981, evento que teve como uma das características a discussão sobre o papel das mulheres no teatro latino-americano durante a ditadura militar brasileira. Sob curadoria da produtora Ruth Escobar, além da participação do Brasil, espetáculos vindos do Chile, Equador e Argentina, países que também estavam sob ditaduras militares, participaram desse evento para discutir o papel da mulher em seus respectivos contextos.

O mote sobre as mulheres na arte teatral serviu como pretexto para a produtora Ruth Escobar enfrentar os pensamentos incrustados dos militares e firmar a posição feminista em sua trajetória.

Palavras-chave: Feminismo; Ruth Escobar; III Festival Internacional de Teatro.

\section{Abstract}

This article aims to discuss some of the theatrical productions of the III International Festival of Theatre (FIT), that took place from the 1st to the 16th of August 1981. Curated by the producer Ruth Escobar, this festival had a distinguishing characteristic because it promoted discussions about the role of women in Latin American theater during the Brazilian military dictatorship.

The event brought together not only Brazilian theatre productions, but also productions from Chile, Ecuador and Argentina, contries which were also facing military dictatorships. These international groups engaged in the discussions about women's role in their contexts of origin. The female performer motif became a justification for producer Ruth Escobar to face the military inscidous ideas and to take a position as a feminist theatre maker.

Keywords: Feminism; Ruth Escobar; III International Theatre Festival.

1 Doutorando do Programa de Pós-Graduação em Teatro (PPGT) da Universidade do Estado de Santa Catarina (UDESC). Dedica-se desde 2009 a pesquisar sobre a trajetória de Ruth Escobar no Teatro Brasileiro.

2 Professora e pesquisadora do PPGT-CEART/UDESC. Orientadora de doutorado de Eder Sumariva. 


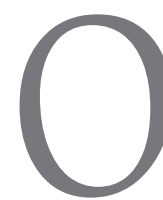

feminismo no Brasil consolidouse entre as décadas de 1960 a 1980 como uma forma de resistência à ditadura militar e contra a ordem política então vigente às mulheres. $\mathrm{O}$ ato de reivindicar direitos em plena excepcionalidade política representou uma "profunda transgressão com o que era designado à época para a mulher" pois "as militantes negavam o lugar tradicionalmente atribuído à mulher ao assumirem um comportamento sexual que punha em questão a virgindade e a instituição do casamento, 'comportando-se como homens', pegando em armas e tendo êxito neste comportamento" (Sarti, 1998) ${ }^{3}$.

No contexto repressivo em que se encontrava o Brasil (1964-1985), Ruth Escobar selecionou grupos teatrais da América Latina para participar do III Festival Internacional de Teatro (FIT) em São Paulo, realizado no período de $1^{\circ}$ a 16 de agosto de 1981, que contou com a presença de dezoito grupos teatrais, além de uma programação paralela composta por intervenções, shows musicais e ciclos de cinema. Com o intuito de realizar uma reflexão sobre a luta da igualdade de direitos para as mulheres, reivindicando mais espaço político e liberdade de expressão para o "sexo frágil", Ruth Escobar levou aos palcos paulistanos produções teatrais de países que também estavam sob uma ditadura militar ${ }^{4}$. A produtora, feminista engajada, enfrentava a ditadura militar brasileira e também lutava contra os maus tratos às mulheres e contra o machismo dos latino- americanos, provavelmente em decorrência de um fato ocorrido em sua vida, como ela mesma relatou:

Não sentia sequer o dilema e me resolvia pela autodestruição, imobilizando minha consciência, minha energia vital, assumindo na plenitude a fêmea medieval.

3 Disponivel em:<http://lasa.international.pitt.edu/LASA98/Sarti.pdf>. Acesso em: 10 abr. 2010.

$4 \quad$ Golpes militares na América Latina na segunda metade do século XX, todos encaminhados como parte da política dos Estados Unidos (EUA) para impedir a expansão da esfera de influência da União Soviética (URSS) na América Latina: Brasi (1964-1985), Chile (1973-1990), Uruguai (1973-1985), Argentina (1976-1983). Além da ditadura do Paraguai (1954-1989).
Na manhã seguinte nos deparávamos com a solução objetiva do cumprimento do pacto. Certamente ele não pretendia me colocar um cinto medieval de couro e ferro. Nós dois, cúmplices, organizamos o artefato. $\mathrm{O}$ cinto seria adaptado em todas as minhas calcinhas, com cadeado, cuja chave ele carregava no pescoço. É claro que as minhas calcinhas não eram biquínis pornográficos, mas calcinhas de filha de Maria indo até a cintura. A partir daquele dia eu, pessoalmente, improvisei em todas elas várias aberturas caseadas, quatro na frente $\mathrm{e}$ quatro atrás, por onde o cinto atravessava rente à cintura.

Consumava-se, mansa e pacífica, minha entrega ao seu canibalismo metafísico. "Se exige esta prova de amor, é porque me ama", pensava eu, orgulhosa da minha devoção.

Me ultrajei, neguei a liberdade de ser eu, neguei a liberdade física de urinar e evacuar, a não ser quando meu amo e senhor estivesse presente. Eu tinha que levantar, tomar banho e pôr meu certificado de propriedade antes do senhor sair de casa. O resultado desse exibicionismo amoroso foram uma tremenda colite intestinal e uma prisão de ventre crônica, à força do controle forçado das necessidades naturais. No teatro, eu me trocava escondida da camareira ou dos olhares de qualquer companheira, para não ser surpreendida com o meu pequeno amuleto do amor. Não consigo mais lembrar quantos meses carreguei essa doença. Por quê? Por quê? - me pergunto hoje.

O homem possui, a mulher se entrega.

Ele me sussurrava no ato: "vou-te possuir", e eu me matava no fanatismo da entrega.

Desejo e morte. Como não ser escrava de quem me dava tanto prazer, interdito ao comum dos mortais? Quantas mulheres cúmplices de tantas mortes, de tantos silêncios, de tanta omissão? 
E, no entanto, essa mulher submissa, quando fora das quatro paredes do quarto, era uma fera, era eu, sua infraestrutura artística, a garantia de que ele, o senhor, pudesse sonhar, criar seus cenários faraônicos, acumular prêmios todos os anos, e, assim, comprovar seu talento de gênio criador e macho dominador (Escobar, 1987, p. 122).

Ao falar de um tempo traumático de sua vida, mesmo que realizado/acontecido com sua aprovação, Ruth Escobar expunha-se e também servia de exemplo. Ao explicar o que fez em "nome do amor", ela possibilitava que as mulheres questionassem a si mesmas ao permitir/ aceitar algo em nome de suposto "amor". Ao denunciar sua passividade e aceitar o ato violento contra sua pessoa, Ruth engajava-se na luta pela liberdade de antigas e medievais amarras que seguram as mulheres e que, muitas vezes, as impediam/impedem de denunciar seus "parceiros".

A passagem descrita por Ruth Escobar ocorreu em 1967, quando estava casada com o cenógrafo Wladimir Pereira Cardoso. Suas palavras demonstram a indignação quanto ao fato de reprimir sua liberdade em prol da satisfação de seu marido, dando-lhe plenos poderes de decisão sobre seus atos. Após esse episódio, declarou Ruth Escobar, "os anos de 1974 e 1975 assistiram ao meu progressivo envolvimento com o movimento de libertação feminina, em paralelo à luta pelo fim da ditadura" (1987, p. 151).

Ainda que sua luta pela causa feminista tenha sido realizada paulatinamente, é interessante apontar que, em 1976, durante o II FIT, a produtora trouxe dois espetáculos que discutiam a condição das mulheres em cena: o espetáculo Nacha de noche, da atriz argentina Nacha Guevara, e a montagem brasileira de Maria Maria, do Grupo Corpo. Mergulhada na reivindicação feminista, Ruth Escobar ampliou a discussão acerca desse mote em voga na época, trouxe para o III FIT (1981) um número maior de montagens que aborda- vam e discutiam a situação da condição da mulher na sociedade ${ }^{5}$.

Convém lembrar para reflexão da época que, na década de 1980, a ditadura militar no Brasil, sob a presidência do General João Batista Figueiredo (1979-1985), demonstrava sinais de esgotamento, mas não de fechamento do ciclo militar. O clima era tenso, e as diferentes tendências entre civis e militares dividiam-se entre o processo de "abertura" ou a manutenção do regime ditatorial. Seu governo, como observa Boris Fausto, "combinou dois traços que muita gente considerava de convivência impossível: a ampliação da abertura e o aprofundamento da crise econômica" (1999, p. 501).

No primeiro ano de seu governo, em agosto de 1979, Figueiredo "tirou das mãos da oposição uma de suas principais bandeiras: a luta pela anistia" (Fausto, 1999, p. 504). Com isso ele conseguiu a aprovação pelo congresso da lei da anistia que impedia revanches e avaliações das ações desencadeadas pelo exército no período da ditadura militar. Mas, como era lei, foi permitido também o retorno ao País dos inúmeros exilados políticos.

\section{As falas e ações feministas no III FIT: Brasil}

Das dezoito montagens cênicas apresentadas no III FIT, privilegiamos nesta análise quatro espetáculos que dialogaram com a problemática feminista e as ditaduras impostas a diferentes países da América latina. Esses espetáculos foram apresentados, portanto, entre $1 .^{\circ}$ e 16 de agosto de 1981, como parte significativa da programação do III FIT.

O ano de 1981, quando Ruth Escobar promoveu o III FIT relacionando feminismo e a luta pelos direitos contra as ditaduras militares da América Latina, seria permeado, Globo de televisão veiculou o seriado Malu Mulher, dirigido por Daniel Filho, no qual enfocava diretamente a temática feminista. As histórias mostram as dificuldades da mulher brasileira, madura e divorciada, a se posicionar na sociedade, na família e em uma relação homem-mulher. Malu sofre diante das dificuldades de uma vida nova. Separada do marido, ela passa por diversas tentativas frustradas na busca de um emprego com o qual pudesse manter a casa e a filha: faz pesquisas, traduções, vende roupas, escreve contos e chega até a cantar em boates. Além disso, ela tem de aprender a conviver com a culpa de deixar a filha sozinha para poder trabalhar. Disponivel em: <www.teledramaturgia.com.br/malu.htm>. Acesso em: 10 abr. 2010. 
no Brasil, por reações da "linha dura", que não concordava com o processo de abertura do regime, mesmo que lenta e gradual.

No primeiro semestre de 1981, terroristas da direita

[...] explodiram bombas em todo o país. $\mathrm{O}$ atentado mais grave não se concretizou: na noite de 31 de abril de 1981, uma bomba explodiu no colo de um sargento, dentro de um carro, no estacionamento do Riocentro (RJ), onde se desenrolava um show comemorativo ao Dia do Trabalho. O caso foi investigado por militares de forma parcial e os envolvidos isentados de culpa. Como os torturadores dos anos 70 , os terroristas da direita ficaram impunes (Bueno, 2003, p. 383).

Em agosto de 1981, o pedido de demissão do chefe da Casa Civil, a eminência parda dos governos militares, general Golbery de Couto e Silva (1911-1987), " teve certamente a ver com a manipulação do inquérito" (Fausto, 1999, p. 505).

Esse relato sobre as pegadas da ditadura militar nos seus momentos de agonia final tem por objetivo situar o leitor e elucidar como foi possível à produtora Ruth Escobar conseguir liberação por parte da censura federal para realizar o III FIT com enfoque em obras com temática explícitas contras as ditaduras latino-americanas.

A produção carioca No natal a gente vem te buscar, ${ }^{6}$ escrita pelo dramaturgo Naum Alves de Souza (1942 -), que também assinou a direção do espetáculo, pode ser compreendida pelo viés do pensamento feminista. A primeira montagem desse texto aconteceu em 1979, na cidade de São Paulo e, no ano seguinte, remontada no Rio de Janeiro; foi "sucesso de bilheteria e, desde sua estreia, em outubro, foi visto por mais de 40 mil pessoas, tendo terminado sua temporada no Rio de Janeiro (Teatro João Caetano) com 1800 pessoas na plateia" (Moreira; Gonçalves, Jornal da Tarde, 10 ago. 1981).

6 Ficha Técnica: Autor: Naum Alves de Souza; Elenco: Marieta Severo (solteirona), Analu Prestes (tia, irmã, mãe), Rodrigo Santiago (primo), Mário Borges (pai); Produção: Marieta Severo e Mário Borges (Telesi; Dias, 1983, p. 85).
A versão carioca de No natal a gente vem te buscar tinha, no elenco, a presença de Marieta Severo, Mário Borges, Rodrigo Santiago e Analu Prestes. As personagens não tinham nomes, eram identificadas por sua função no interior do núcleo familiar. A dramaturgia era "centrada na história de uma solteirona, sua vida quando criança, adolescente, adulta e o seu relacionamento com os outros integrantes da família" (Moreira; Gonçalves, Jornal da Tarde, 10 ago. 1981). A crítica Ilka Marinho Zanotto, a respeito da dramaturgia, escreveu:

Valendo-se de um argumento aparentemente banal [...], o autor traça um dos mais agudos e pertinentes perfis da realidade brasileira. Mergulhando no cotidiano, no usual, no comum de nossa vivência, analisa-o com sutileza e profundidade ao captar-se as minúcias superficiais e as correntezas subterrâneas que raramente afloram à tona. Caracteriza exemplarmente as semelhanças que identificam personagens e espectadores ao mesmo tempo em que constrói os primeiros, segundo a lógica da mais admirável ficção (Zanotto, 1981). ${ }^{7}$

Naum Alves de Souza conseguiu captar, mediante a observação do ambiente familiar de sua própria vivência e entorno, vários tipos de ritos que os núcleos familiares praticavam, proporcionando identificação entre palco-plateia, pois o tema abordado estava em consonância com os espectadores. Para o crítico Yan Michalski, "o autor tem uma qualidade rara na dramaturgia brasileira: a do 'understatement', da capacidade de dizer explicitamente pouco para insinuar muito" (Michalski, 1980, In: Peixoto, 2005, p. 359360). O crítico Sábato Magaldi destacou o trabalho interpretativo do elenco:

7 Verbete No natal a gente vem te buscar. In: Enciclopédia Itaú Cultural. Disponivel em: <http://www.taucultural.org.br/aplicexternas/enciclopedia_teatro/index. $\mathrm{cfm}$ ?fuseaction=espetaculos_biografia\&cd_verbete $=4079 \&$ Ist_palavras $=\& c d \_i d i o-$ $\mathrm{ma}=28555$. Acesso: 23 mar. 2013. 
Marieta Severo compõe a solteirona com um cuidado que dá empostação vocal à maneira de andar, privilegiando a verdade interior. Analu Prestes, menos segura na tia velha, se transfere com total precisão da irmã sedutora para a mãe conformada. Rodrigo Santiago tem a justa sensibilidade como o primo órfão, 'mal-agradecido', morto pela repressão sem ter exercido nenhuma liderança. E Mário Borges cria do pai a figura patética. Elenco de perfeito entrosamento, que dá as personagens sua real dimensão (Magaldi, Jornal da Tarde, 12 ago. 1981).

A ação da personagem de Marieta Severo era o ponto de apoio dos dilemas enfrentados pelos familiares, além de ser responsável pelos demais membros da família. Sua personagem representava, em uma acepção feminista, a necessidade de reivindicar reconhecimento e um lugar de prestígio no seio familiar e na sociedade. Já as outras personagens não praticavam nenhuma relação de poder, não possuíam voz e nem espaço, tarefa essa executada pela liderança da solteirona. Nesse sentido, as personagens de Rodrigo Santiago e Mário Borges serviam como antagonistas para reforçar a necessidade de haver um chefe familiar; a mulher poderia (e devia) assumir esse posto de chefia.

Ilka Marinho Zanotto destacou o desempenho dos atores. Ela escreveu:

Como diretor, contou também na atual montagem com elenco de exceção. Marieta Severo, Rodrigo Santiago, Analu Prestes e Mário Borges transcendem a interpretação pura e simples de criaturas de ficção para viverem em cena instantes mágicos de criação autônoma. [...] A 'solteirona', vivida por Marieta Severo com espantosa fidelidade a um tipo minuciosamente construído, já se inscreve na galeria de personagens de nossa dramaturgia como um dos mais patéticos e comoventes. O 'primo-irmão de criação' tem em Rodrigo Santiago um interprete à altura de sua figura quase heróica na solidez e na coragem que nãolhe bastaram, todavia, para escapar a um destino absurdo o mesmo de tantas vítimas dos anos de repressão. Analu Prestes interpreta personagens diversos com tal força que acreditamos tratar-se de atrizes diferentes. E Mário Borges é uma esplêndida revelação para nós, paulistas, um ator completo (Zanotto, $O$ Estado de São Paulo, 13 ago. 1981).

Com um conjunto de atores afinados e entregues às personagens, a encenação No natal a gente vem te buscar fez três apresentações na Sala Gil Vicente: duas sessões no dia 10 de agosto às 21e 24 horas e uma sessão no dia seguinte às 21 horas. Para essas apresentações, os ingressos custavam trezentos cruzeiros - preço único para todos os espectadores, apresentações que encerraram definitivamente essa produção cênica, conquistando os críticos e o público paulista.

\section{Quatro mulheres e a ditadura de Augusto Pinochet}

Outro grupo que trouxe o mote feminista em forma de espetáculo foi o grupo chileno Taller de Investigacion Teatral (TIT). Com autoria de David Benavente e direção de Raul Osorio, Tres Marias y Una Rosa (1979) ${ }^{8}$ (Figura 1) foi apresentado no Teatro Galpão de 6 a 9 de agosto, sempre às 21 horas. $\mathrm{O}$ ingresso custava entre duzentos e setecentos cruzeiros. O diretor Raul Osorio pretendia "mostrar quatro mulheres que unificam suas tragédias familiares, superam seus individualismos e para um trabalho conjunto, uma tela gigante com um tema alegórico sobre o Juízo Final, porém, à moda chilena" (Gonçalves Filho, Folha de São Paulo, 06 ago. 1981).

8 Ficha Técnica: Autor: David Benavente e Taller de Investigacion Teatral; Direção: Raul Osorio; Cenografia e iluminação: Ranon Lopez; Programa e cartaz: Milry Ann Streeter; Desenho e realização da "Arpillera" - Manolé Munoz. Aria Uribe, Maria Cornejo e Soia Roquelme; Música: Patricio Solovera; Fotografia: Ranon Lopez; Figurinos: as atrizes; Direção de cena: Claudio Pueller; Realização de iluminação: Carlos Cabezas; Cenotécnico: Alejo Carrasco; Elenco: Luz Gimenez (Maruja), Loreto Velenzuela (Maria Ester), Miriam Palacios (Maria Luiza), Soledad Alonso (Rosa); Produção e administração: David Benavente (Telesi; Dias, 1983, p.89). 


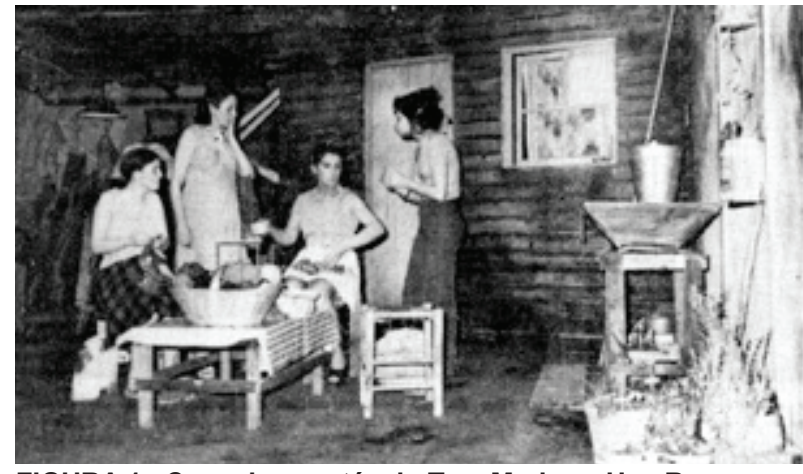

FIGURA 1 - Cena do espetáculo Tres Marias y Una Rosa, apresentado no III Festival Internacional de Teatro.9

A ditadura militar chilena (1973-1990), sob o comando do ditador Augusto Pinochet (1915-2006), ficou marcada como sendo uma das mais violentas da América Latina, com um número expressivo de torturados, mortos e exilados. Em 2011, a Comissão de Valech $^{10}$ entregou um novo relatório sobre o número de vítumas: "[...] o total de vítimas oficiais entre executados, desaparecidos e torturados durante os 17 anos que durou a ditadura de Pinochet (1973-1990) subiu para 40.280, apesar de entre os grupos de vítimas se estimar que a cifra possa superar os $100.000^{\prime 11}$. Foi nessa condição sociopolítica que o espetáculo Tres Marias y Una Rosa foi concebido, causando, na visão dos jornalistas chilenos, uma afronta ao governo militar de Augusto Pinochet. A encenação "veio constituir um novo motivo de inquietude no que se refere aos ataques ao governo militar, perpetrados de atividades artísticas. A análise agrega que esta obra é de boa qualidade. De todas as exibidas até o momento, é a de maior temática política com alusões claras e diretas" (ARTE, Hoy, 26 set.) ${ }^{12}$.

Além do tom crítico atribuído ao espetáculo, os críticos chilenos também destacaram o trabalho interpretativo desenvol-

\footnotetext{
9 Disponivel em: <http://www.santiagoamil.cl/?p=138>. Acesso: 24 mar. 2013.

10 A comissão recebeu esse nome em homenagem ao Bispo Sergio Valesch, importante representante da luta dos Direitos Humanos durante o período ditatorial de Pinochet. Foi criada em 2003 com o objetivo de investigar a violação dos Direitos Humanos. Também conhecida como Comissão Nacional sobre Prisão Política e Tortura.

11 Disponivel em: <http://g1.globo.com/mundo/noticia/2011/08/novo-relatorio-sobepara-mais-de-40000-as-vitimas-da-ditadura-de-pinochet.html>. Acesso em: 23 mar. 2013.

12 o jornalista alega que "ha venido a constituir um nuovo motivo de inquietud en lo que se refiere a ataques al gobierno militar, perpetrados de actividades artísticas. $E$ análisis agrega que "esta obra es de buena calidad. De todas las exhibidas a la fecha, es de la mayor temática política y com alusiones claras y directas"' Disponível em: <http://www.santiagoamil.cl/es/?p=138>. Acesso em: 25 mar. 2010.
}

vido pelo grupo; "o mais surpreendente ao público na noite de estreia foi o realismo com que as atrizes encarnam as humildes artesãs. Alcançaram resultado depois de vários meses de trabalho na população Lo Hermida, onde conheceram quatro mulheres, que elas se encarregam de reviver" (PODER feminino, La Tercera, 02. ago. $1979)^{13}$.

Fundado em 1976, o grupo Taller de Investigacion Teatral trabalhava com um sistema cooperativado, não recebia subsídios governamentais. A plataforma ideológica explicitava o objetivo a cumprir:

A função de resgatar documentos e testemunhos de situações, tensões, conflitos, relações, vivências e visão de mundo, que se encontram atualmente em determinados setores sociais chilenos. Desta maneira, o produto teatral e sua documentação é o resultado de uma investigação da realidade sistematicamente orientada.

Este trabalho de investigação realiza-se por meio da observação participante dos membros do TIT, no interior das realidades, que se escolheu reconhecer e registrar. Procura-se também penetrar mais além das aparências, com a participação vivencial das realidades concretas dos grupos sociais com os quais se trabalha.

Esta escolha implicou no desenvolvimento de uma metodologia da observação, que se traduz num conjunto de exercícios que permitem a observação do material registrado. Através das memórias físicas, sensoriais e emotivas, das atitudes, gestos, ações, linguagem verbal, das relações com lugares, objetos, pessoas, etc., o TIT vai transformando o material observado em material teatral, sobre o qual é criada posteriormente a obra dramática, a direção e a interpretação (Programa, 1981). 
A metodologia de trabalho adotada pelo grupo foi aplicada ao espetáculo Tres Marias y Una Rosa ${ }^{14}$. Durante um ano, as atrizes acompanharam as mulheres artesãs que viviam na periferia de Santiago. O processo de montagem foi resultado de uma criação elaborada com base na observação e vivência de integrantes do TIT junto a tecelãs de uma área marginal de Santiago. Esse comércio foi instituído na década de 1970 como uma alternativa financeira para as mulheres e suas famílias conseguirem sobreviver à elevada taxa de desemprego e à repressão policial/ militar. Esse movimento teve o apoio da igreja independente católica do Chile.

Nessa comunidade, as integrantes do grupo puderam observar as relações estabelecidas entre os moradores, o modo como trabalhavam para sustentar suas famílias com o trabalho artesanal e as características da cultura local. O objetivo da observação e convivência era não falsear a representação cênica a respeito do modo de vida das mulheres tecelãs que viviam na periferia da capital. Isso resultou num espetáculo que levou "às ultimas consequências a realidade das personagens e de seu estilo pessoal" (Magaldi, Jornal da Tarde, 8 ago. 1981, p. 14). O espetáculo mostra quatro mulheres da população marginal que fazem artesanato (tecelagem) para conseguir sustentar suas famílias, cujos maridos encontramse desempregados ou partiram para o exterior

\section{Soy hija de la rabia y del grito: Maria Escudero' ${ }^{15}$}

Do Equador, veio o grupo Saltamontes com o espetáculo Pedro Manso (1979) (Figura 2), sob a direção de Maria Escudero (1926-2005). Escudero foi atriz, cantora, diretora, professora de teatro, pertenceu e ajudou a fundar o Departamento

14 o espetáculo Tres Marias y Una Rosa ficou em cartaz durante quatorze meses no Chile e foi assistido por mais de cinquenta e cinco mil espectadores. Com o sucesso de público e crítica, o grupo chileno realizou uma turnê internacional, passando pelos Estados Unidos, Canadá, Venezuela, Inglaterra e França.

15 Fala de Maria Escudero ao receber o Prêmio Manuela Espejo. Disponivel em: <http://clon.uam.mx/spip.php?article497>. Acesso em: 23 mar. 2013. de Teatro da Universidade Nacional de Córdoba (Argentina). Quando professora, "em 1969 foi expulsa da faculdade". Nesse tempo, ela já tinha formado o grupo Libre Teatro Livre, que era composto por alunos e ex-alunos e por "dedicados diretores do teatro de Córdoba" (Zaballa, 2013). Contudo, em 1999, Maria Escudero "foi homenageada no Festival del Libre Teatro Libre de Córdoba que para tal ocasião incluiu a principal temática do encontro 'O TLT, Maria Escudero e a crição coletiva hoje". E a "Universidade $\mathrm{Na}$ cional de Córdoba, que trinta anos antes havia expulsado a professora de teatro, pediu desculpas e lhe outorgou o doutorado Honoris Causa"16.

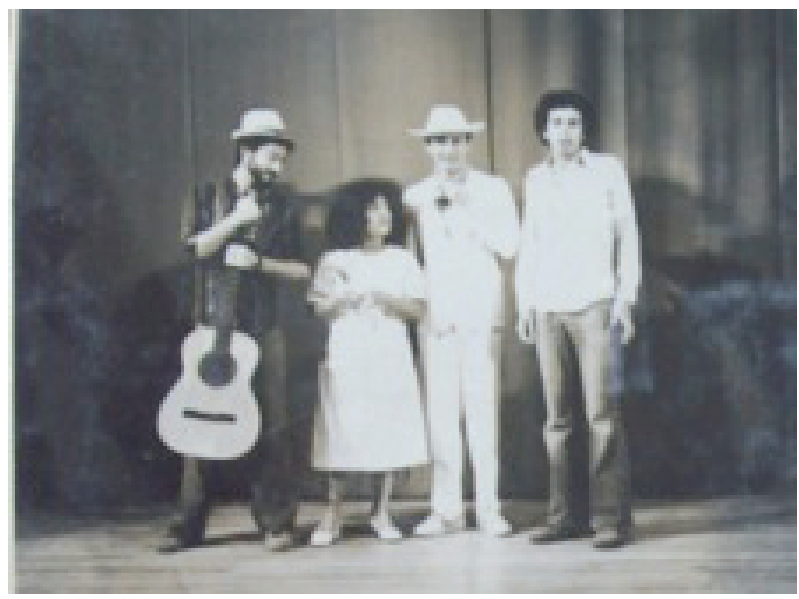

FIGURA 2 - Cena do espetáculo Pedro Manso Acervo Ruth Escobar

Com o golpe militar na Argentina, em 24 de março de 1976, a diretora, por medida de segurança, decidiu exilar-se no Equador. Ao chegar ao Equador, Maria Escudero (Figura 3) "continua com sua proposta, funda o Saltamontes, trabalha com mulheres por seus direitos; em um empenho persistente para transmitir e fazer que se descubram humanas, sensíveis e fortes para enfrentar a violência, entre outras

16 De acordo com a reportagem "En 1999 fue homenajeada en el Festival del Libre Teatro Libre de Córdoba que para tal ocasión incluyó la principal temática del encuentro: "EL TLT, María Escudero y la Creación Colectiva Hoy". La Universidad Nacional de Córdoba, que treinta años antes la había expulsado de la cátedra de teatro, le pidió disculpas y le otorgó el doctorado Honoris Causa". TORAL, Genoveva Mora. Maria Escudero. Disponivel em: <http://www.mandragorateatro.org/index.php?option=com_con tent\&view=article\&id=154\&ltemid=78> Acesso em: 23 mar. 2013 
vicissitudes"17. Tanto com o Libre Teatro Libre, quanto com o grupo Saltamontes, Escudero sempre teve, como princípio de trabalho, a criação coletiva para a construção de espetáculos comprometidos, abordando temas políticos e a problemática da violência familiar.

O espetáculo Pedro Manso foi apresentado nas dependências do Teatro Oficina, e o elenco era formado por Juan Gabriel de la Roche, Diego Naranjo, Augusto Escotto e Maria Escudero. A encenação contava a história de um jovem casal que, apesar de a mulher ser autoritária, o poder de dominação do marido era maior em virtude do ato viril que executava: ele deveria matar um galo na primeira noite de núpcias como forma de demonstrar sua virilidade e poder. A temática central da encenação serviu para discutir o machismo e o autoritarismo disseminado na população latino-americana em decorrência dos golpes de Estado. As atitudes e comportamentos dos generais refletiam-se na postura dos cidadãos, a norma e o exemplo deviam ser seguidos por todos.

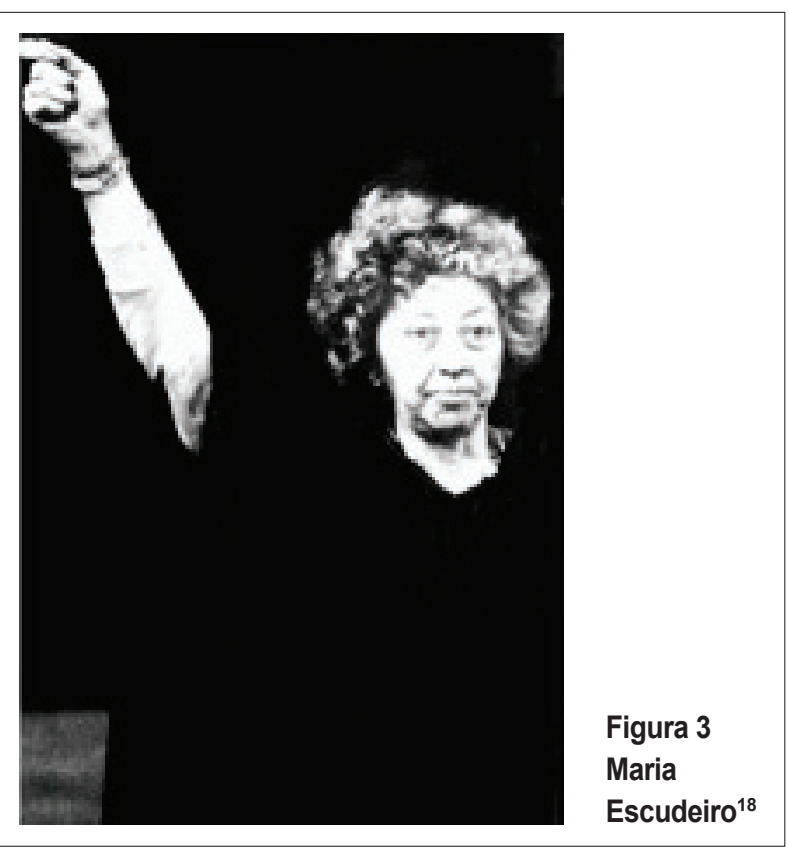

17 A reportagem diz que quando Escudero "Llega a Ecuador y continúa con su propuesta, funda Saltamontes, trabaja con las mujeres por sus derechos; en un empeño persistente por transmitirles y hacer que se descubran humanas, sensibles y fuertes para enfrentar la violencia, entre otras vicisitudes". Disponível em: <http://www.mandragorateatro.org/index. php?option=com_content\&view=article\&id=154\&ltemid=78> Acesso em: 23 mar. 2013

18 Disponivel em: <http://www.mandragorateatro.org/index.php?option=com_content \&view=article\&id=154\&ltemid=78>. Acesso em: 23 mar. 2013.
O cenário do espetáculo Pedro Manso era composto somente por um único banco, "a parcimônia de recursos utilizados e o resultado excelente devem fazer muitos artistas de teatro daqui pensarem, antes de justificar a má qualidade de seu trabalho por causa da "falta de verbas'" (FILO, Revista Teatro, jul/ago. n. 5 de 1981). Para o crítico Clóvis Garcia, “o espetáculo é despojado de qualquer elemento desnecessário, com apenas acessórios cênicos e figurinos modestos. Mas o elenco [...] consegue, dentro de uma linha interpretativa quase ingênua, lembrar as comedinhas de nossos circos, realizar um trabalho teatral denso de poesia, comunicação e teatralidade popular" (Garcia, O Estado de São Paulo, São Paulo, 7 ago. 1981, p. 21). Utilizandose de recursos cenográficos simples e por empregar uma linguagem compreensível ao público, Pedro Manso proporcionou aos artistas e espectadores paulistanos um espetáculo envolvente, "sente-se que os interpretes falam de fato a língua do povo e não cogitam de impor às camadas populares uma visão particular do que seria melhor para elas. A singeleza da apresentação se transmuda, como que por encanto, em delicioso prazer estético" (Magaldi, Jornal da Tarde, 07 de ago. 1981).

\section{Com mi arte quiero servir a la gente ${ }^{19}$ : Cipe Lincovski}

Para o encerramento do III FIT, a produtora Ruth Escobar repetiu a mesma ideia do festival anterior, realizado em 1976, chamando uma artista para realizar a apresentação final. Nessa ocasião, convidou a argentina Cipe Lincovski (1933-) (Figura $4)$, militante política que desafiou as autoridades argentinas realizando espetáculos politizados.

A Sala Gil Vicente do Teatro Ruth Escobar, em 13 de agosto, recebeu o espetáculo Yo Quiero Decir Algo (Eu Quero Dizer Algo); o espaço teatral foi transformado num cabaré, cenário em que a atriz recitava textos

\footnotetext{
19 Frase pronunciada por Cipe Lincovski durante entrevista concedida ao jornal La Gaceta, da Argentina. Disponível em: <http://www.lagaceta.com.ar/nota/390751/cipelincovsky-con-mi-arte-quiero-servir-gente.html>. Acesso em: 23 mar. 2013
} 
de Bertolt Brecht (1898-1956), Anton Tchecov (1860-1904), Oliverio Girondo (18611967), Pablo Neruda (1904-1973) e Thiago de Mello (1926 -) em forma de colagem, dirigido pela própria Cipe Lincovski.

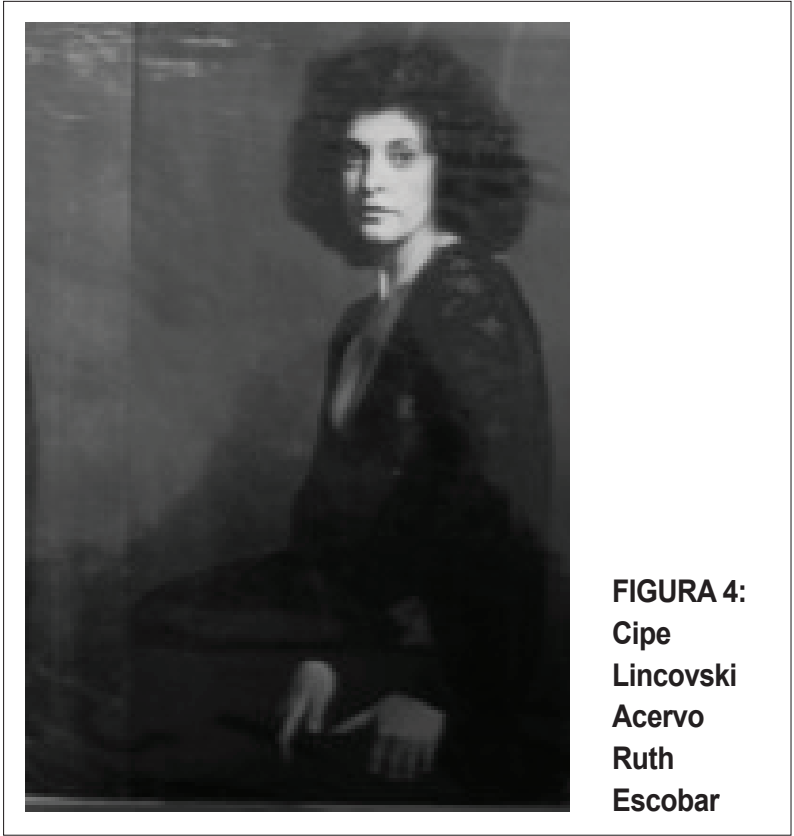

Acompanhada pelos músicos Edgardo Snuecoul (piano e órgão), Pablo Greco (bandoneón) e Estevan Morgado (guitarra), Cipe apresentou um monólogo repleto de deboche portenho com "permanentes referências - irônicas ou agressivas - aos temas políticos da atualidade, sobretudo nacional" (Zanotto, O Estado de São Paulo, 15 ago. 1981, p. 16). Com provocações à ditadura militar em seu espetáculo, Cipe foi perseguida pela máquina repressiva do Estado argentino, consequentemente, viu-se obrigada a conseguir abrigo político, nesse caso, na Espanha. O próprio nome do espetáculo indicava que a artista expunha sua opinião contra a imposição das rígidas regras que os militares impuseram à Argentina, assim como em outros países da América Latina. Nesse sentido, o espetáculo de protesto de Cipe pode ser compreendido como a voz dos cidadãos de outros países que sofreram consequências dos "anos de chumbo".

O crítico Sábato Magaldi definiu-a como "um dos poucos monstros sagrados do palco atual. Em seu desempenho, há uma decantação de todos os meios inter- pretativos que envolvem ininterruptamente o público" (Magaldi, Jornal da Tarde, 15 ago. 1981, p. 14). Cipe ainda utilizou diversos recursos vocais para valorizar sua comunicação com o público, sua voz era "poderosa, aveludada, tirando um partido maior dos tons graves, [no entanto,] o espetáculo parece uma colcha de retalhos, destinado a colocar no primeiro plano o virtuosismo da intérprete" (Magaldi, Jornal da Tarde, 15 ago. 1981, p. 14).

\section{Retro[expectativa]}

Por fim, é interessante destacar que a presença de espetáculos que dialogavam com o mote proposto pela produtora Ruth Escobar, no início da década de 1980, reivindicando espaço e voz, foram encenações que representavam seus respectivos contextos, ao mesmo tempo em que correspondiam a fatos semelhantes em outros locais da América Latina. Nesse sentido, pode-se perceber que Ruth Escobar estava atenta às questões sociais que perpassavam em vários países, propondo, por meio de apresentações teatrais, a reflexão do público sobre o papel da mulher na sociedade. Outro fator importante para que esses espetáculos (e muitos outros) estivessem presentes em São Paulo no III FIT era a significativa rede de contatos que Ruth Escobar possuía com relevantes pessoas em diferentes espaços sociais e artísticos da América Latina. Ela estava vinculada e envolvida com as lutas sociais e feministas travadas pelas mulheres do continente americano.

É relevante salientar que dois quartos (2/4) dos espetáculos que trataram da temática feminista foram dirigidos por mulheres, função geralmente ocupada por diretores/encenadores. Assim como Ruth Escobar, Maria Escudeiro e Cipe Lincovski foram militantes em seus respectivos países pela luta contra a ditadura militar, utilizando o teatro como forma de protesto e denúncia dos atos ditatoriais. Na programação do III FIT, ainda consta a presença de outras mulheres artistas: a dança coral, de Solange Camargo, o espetáculo solo $A$ poesia do silêncio, de Denise Stoklos, e Isaura 
de Assis, que assinou a direção de Procissão dos miseráveis. A partir da realização desse festival, Ruth Escobar foi impulsionada a promover o I Festival Nacional das Mulheres nas Artes, realizado em 1982. Além disso, durante a década de 1980, a produtora tornou-se deputada estadual em São Paulo, tendo em sua plataforma política a reivindicação pelos direitos das mulheres, tornando-se, em 1985, a primeira presidente do Conselho Nacional dos Direitos da Mulher. 


\section{REFERENNCIAS}

ARTE nacionalista. Hoy, 26 setiembre al 02 octubre de 1979, p. 16-17.

BUENO, Eduardo. Brasil: uma história. São Paulo: Ática, 2003.

ESCOBAR, Ruth. Maria Ruth. Rio de Janeiro: Editora Guanabara, 1987.

GONÇALVES FILHO, Antonio. A luta pela democracia em mais duas estréias. Folha de São Paulo, São Paulo, 06 de agosto de 1981.

FAUSTO, Boris. História do Brasil. São Paulo: Edusp, 1999.

FI-LO porque qui-lo. Revista Teatro, São Paulo. jul/ago. n. 51981.

GARCIA, Clóvis. Galpon e Saltamontes, o bom teatro em cena. O Estado de São Paulo, São Paulo, 07 agosto de 1981, p. 21.

MAGALDI, Sábato. A realidade chilena, vista com humor. Jornal da Tarde, São Paulo, 08 de agosto de 1981, p. 14.

MAGALDI, Sábato. Cipe Lincovsky: um privilégio poder vê-la e ouvi-la. Jornal da Tarde, São Paulo, 15 de gosto de 1981, p. 14.

MAGALDI, Sábato. O bom reencontro com a obra de Naum. Jornal da Tarde, São Paulo, 12 de agosto de 1981.

MAGALDI, Sábato. O encanto e a vivacidade deste grupo: uma festa. Jornal da Tarde, São Paulo, 07 de agosto de 1981.

MICHALSKI, Yan. Pequenos rituais de um Natal que não virá. Jornal do Brasil, Rio de Janeiro. 11 de outubro de 1980. In: PEIXOTO, Fernando (Org.). Yan Michalski: Reflexões sobre o teatro brasileiro no século XX. Rio de Janeiro: FUNARTE, 2004.

MOREIRA, Araújo. GONÇALVES, Marli. A peça de Naum, em três apresentações, Jornal da Tarde, São Paulo, 10 de agosto de 1981.

PODER FEMININO triunfa em el Teatro "Del Angele", La Tercera, 02 de agosto de 1979 , p. 56.

PROGRAMA do III Festival Internacional de Teatro, São Paulo, 1981. Artigo do Programa.

SARTI, Cynthia A. O início do feminismo sob a ditadura no Brasil: o que ficou escondido. Disponível em: <http://lasa.international.pitt.edu/LASA98/Sarti.pdf>. Acesso em: 10 abr. 2010.

TELESI, Silvia Fernandes; DIAS, Lineu Moreira (Org.). Anuário das artes cênicas: dança/ teatro 1981. Secretaria Municipal de Cultura de São Paulo: Centro Cultural São Paulo, 1983.

TORAL, Genoveva Mora. Maria Escudero. Disponível em: <http:/ /www.mandragorateatro.org/index.php?option=com_content\&view=article\&id=154\&Itemid=78>. Acesso em: 23 mar. 2013. 
ZABALA, Fernando. Maria Escudero y su Teatro Libre. Disponível em: <http://clon. uam.mx/spip.php?article497>. Acesso em: 23 mar. 2013.

ZANOTTO, Ilka Marinho. Verbete No natal a gente vem te buscar. Enciclopédia Itaú Cultural. Disponível em: <http:/ / www.itaucultural.org.br/aplicexternas/enciclopedia_teatro/index.cfm?fuseaction $=$ espetaculos_biografia\&cd_verbete $=4079 \& l s t \_p a l a v r a s=\& c d$ _ idioma=28555>. Acesso em: 23 mar. 2013.

ZANOTTO, Ilka Marinho. Brasil, autor da magia que brilhou no festival. O Estado de São Paulo, São Paulo, 13 de agosto de 1981.

ZANOTTO, Ilka Marinho. Voz, humor e a vibração humana de atriz maior. O Estado de São Paulo, São Paulo, 15 de agosto de 1981, p. 16. 